ORNL/TM--12163

DE93 000835

\title{
PREPARING EBS MESSAGES
}

\author{
Barbara M. Vogt \\ John H. Sorensen \\ Prepared for \\ Chemical Stockpile Emergency Preparedness Program \\ Public Affairs Committee
}

September 1992

Prepared by the Oak Ridge National Laboratory

Oak Ridge, Tennessee 37831 managed by

Martin Marietta Energy Systems, Inc.

for the

U.S. DEPARTMENT OF ENERGY

under Contract No. DE-AC05-84OR21400

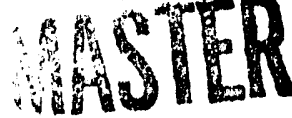

DISTRIBUTION OF THIS DOCUMENT IS UNLIMITED 


\section{TABLE OF CONTENTS}

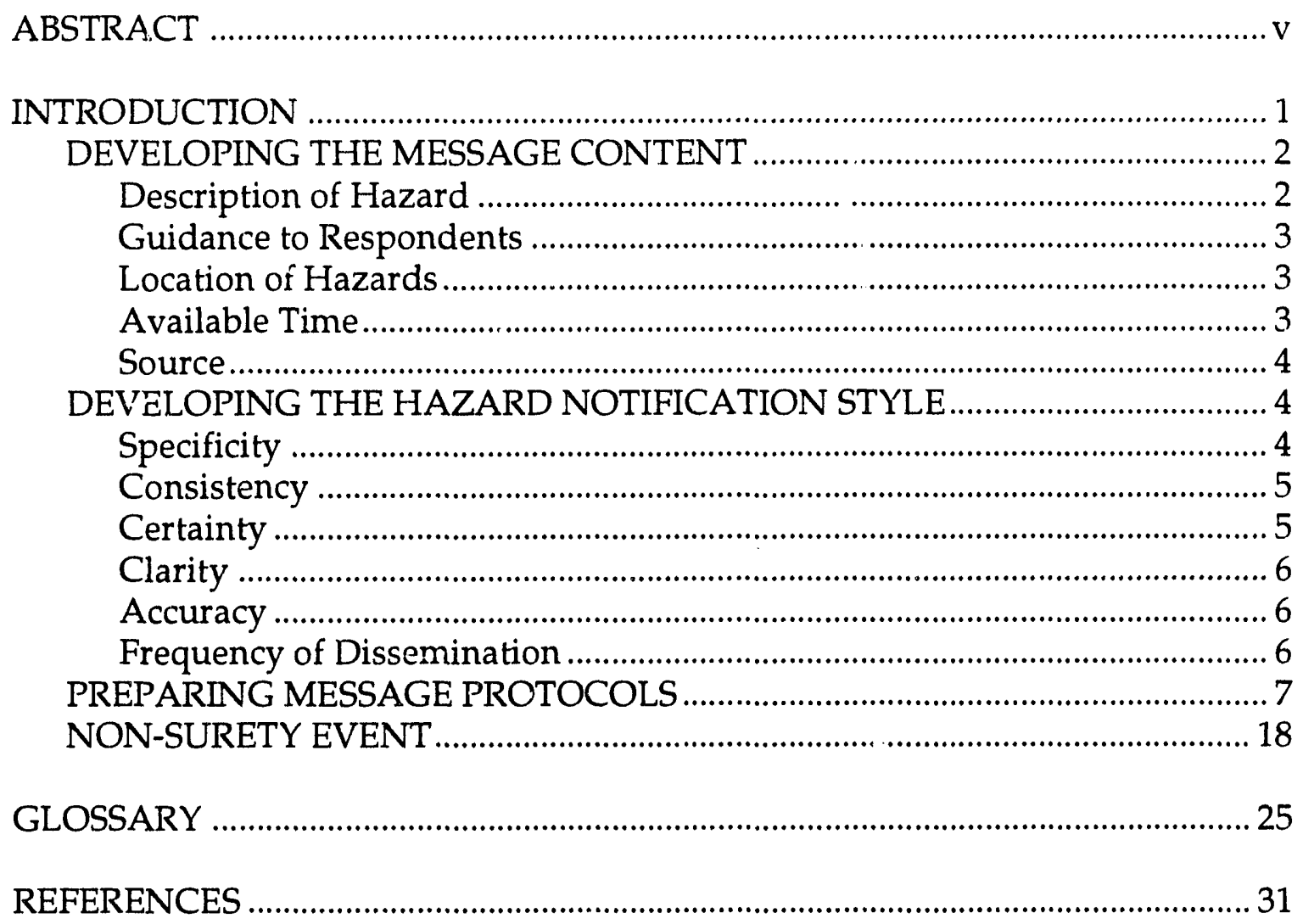




\begin{abstract}
Warning messages transmitted to populations at risk from an accidental release of chemical agent must be carefully designed to maximize appropriate responses from iffected publics. This guide develops an approach for preparing Emergency Broadcast System (EBS) messages for the Chemical Stockpile Emergency Preparedness Program (CSEPP). Sample messages illustrate the application of this approach. While the sample messages do not cover every emergency situation, the texts are generic in that accident and location-specific factors can be incorporated into the final message developed by local emergency planners. Thus they provide a starting point, not an end product, for emergency planners.
\end{abstract}




\section{INTRODUCTION}

Alert/notification messages are very important elements of the warning effort. Past experience shows that the content, style and other elements of the hazard notification messages have direct impact on human response to a warning in general and the willingness to comply with recommended protective actions in particular. Planning efforts should be undertaken to prepare messages with clarity, precision and authority. The sections below present information on the state of the art in message preparation. Much of this material was drawn from a report prepared by D. Mileti and J. Sorensen, Communication of Emergency Warnings: A Social Science Perspective and State-of-the-Art Assessment (Oak Ridge National Laboratory 1990).

Social scientists have been studying human response to warnings for more than 25 years. They have found that public response to an emergency warning will increase:

a. as the specificity of hazard notification messages (location at risk, guidance about public response, the impending hazard, and time of accident) increases;

b. as the consistency within and between different hazard notification messages is maintained; and

c. when the notification message is stated clearly.

One of the clearest and most consistent conclusions of research in this area is that the hazard notification message is one of the most important factors in determining the effectiveness of a community warning system. It is the content and style of the hazard notification message that largely shapes the extent to which the endangered population in a community engages in protective actions.

This guide develops an approach for preparing Emergency Broadcasting System (EBS) messages for the Chemical Stockpile Emergency Preparedness Program (CSEPP). Sample messages are provided to illustrate the application of this approach. While the samples do not cover every emergency situation that could arise, they are generic in that location-specific 
factors can be incorporated with appropriate changes in text. Thus, the guide is a starting place for local planners, not a finishing point.

\section{DEVELOPING THE MESSAGE CONTENT}

Five important factors should be considered in assembling the content of the hazard notification message:

a. description of hazard or risk,

b. guidance to the population of what to do,

c. location and the origin of hazard,

d. information on time, with regard to how much time is available for the respondents to take protective action, and

e. source of the hazard notification message.

\section{Description of Hazard}

A hazard notification message should provide the public with carefully selected and salient facts about the impending hazard. The notification message should describe the chemical accident that may occur or has occurred, and inform respondents why the accident is hazardous to them. For example, it is insufficient for a notification to simply state that a toxic gas leak has occurred. The notification message should also describe the volume of the roxic gas released (e.g., a ton container), the speed with which the gas cloud moves towards community, and the general location of the release.

The general point in describing a hazard is to provide sufficient detail so that all respondents in a community understand the physical character of the disaster from which they are to protect themselves. Notification messages that are vague regarding the hazard result in various segments of the population defining the hazard in very different ways. This can result in some people making poor protective action decisions. Providing information about the hazard's physical characteristics in notification messages will reduce the number of persons who don't understand the hazard or who may take improper response actions. The hazard aspect to notification message content provides the respondents with a "why" rational for subsequent protective behavior. 


\section{Guidance to Respondents}

The hazard notification messages should also contain instructions concerning what people should do in response to a hazard. Hazard notification messages should provide guidance on how to assure safety in the face of impending hazard. People will respond more effectively with an appropriate protective action when proper guidance is provided. Explicit instructions for protective action must therefore be given to the respondents. On the surface, this point may seem obvious, but it is often overlooked in practice. For example, information given in warnings must do more than tell people in danger that they should evacuate. Evacuate for some may mean leaving the house and going to the front yard. Instead, the process should be explicitly defined. For example, a message could state "All residents in the affected area should evacuate on Route 6 until you are in Friendly Township."

\section{Location of Hazards}

Hazard alert and notification messages should also tell people the specific geographic areas in a community that are at risk as well as those areas not under threat. That is, both the population at risk and those not at risk must be addressed in the hazard alert and notification messages. For example, the warning could say: "The only affected area of town is betweeit Second and Fifth Streets from Elm Avenue to Magnolia Boulevard. The rest of the town will not be affected."

\section{Available Time}

Hazard notification messages should also include information on the available time the respondents located in specific areas of the community will have to engage in appropriate protective actions before the released chemicals reach the community. For example, a message could state: "The accident conditions will be serious after 10:00 p.m. this evening, and you should be past the eastern border of the county line by 9:45 p.m. to be on the safe side." 
Source

Those persons responsible for issuing a hazard alert for the community should be clearly identified in the hazard notification message. The purpose of providing this information is to convince respondents that the hazard alert and notification messages are issued by knowledgeable authorities, that the chemical accident is real, and that the event presents potential for grave harm if those affected do not take the recommended protective actions. The best sources for the hazard notification are individuals who represent political as well as scientific/technical organizations. There is no one credible source of information that will be believed by everybody, especially in warnings directed toward a heterogeneous population. A mix of ind viduals who represent political as well as scientific/technical organizations enhances credibility. The hazard notification message should identify the individuals by name, identify their positions, and state the names of their organizations or offices.

\section{DEVELOPING THE HAZARD NOTIFICATION STYLE}

The hazard notification message should be written in a style that clearly conveys to the respondents the potential hazard. There are five issues regarding the style of the notification message that require brief discussion.
a. specificity;
b. consistency;
c. accuracy;
d. certainty; and
e. clarity.

\section{Specificity}

Hazard notification messages should be very specific. Specifically recommending hazard mitigation measures, sta ting the precise character of the hazard, and indicating how much time the respondents have to engage in protective actions, results in prompt reaction by the community and the execution of the appropriate protective measures. The content of the hazard 
notification message must be very specific in this regard. On those occasions in which specificity on all content items cannot be detailed (because details are unknown $r$ only known approximately), the warning message itself and the style with which it is written must still remain as specific as possible. For example, the message could state: "We do not know nor can it be known which buildings in the city are the safest for sheltering, but we do know that most everyone will be protected if they shelter inside buildings and do not attempt to leave the building or evacuate from the area in which they are located."

\section{Consistency}

Hazard notification messages must also be consistent, both within a single message and across different messages. Messages should also be consistent in describing the actions being taken. For example, a message telling respondents to remain indoors and await further information is of little help if the respondents observe that families of community emergency personnel are leaving their residences. It is important to avoid any inconsistencies across different messages. As the crisis progresses and more is learned about the potential hazard(s), hazard notification updates should be issued. These updated notification messages in turn must be consistent with the previous notification messages. Consistency can be rendered across notification messages by referencing and/or repeating the information in the previous message(s), by clearly stating the additional information on the hazard(s), and by pointing out the changes from the previous messages along with a brief explanation for the basis in such changes.

\section{Certainty}

Hazard notification messages should be written with as much certainty as possible, even in circumstances in which there is ambiguity associated with the chemical accident's impact on the community. Where there are low probabilities or ambiguities associated with a hazard's impact, the message should be stated with certainty, even when discussing the ambiguity. For example, the message could say: "There is no way for us to know if there really is going to be an explosion in the plant, but we have decided to 
recommend that everyone in the immediate response zone (IRZ) be evacuated now; everyone should act as if the explosion is a real threat." Certainty in warning messages, however, extends beyond the actual message content. Certainty also includes the style with which the message is delivered to a public. The warning $"$ :essages should be read by spokespersons in a tone of firm belief that convey the impression that he/she believes they are certain about what is being said in the message.

\section{Clarity}

Hazard notification messages must be worded in a language that can be understood by all respondents. Avoid the use of complex scientific or engineering terminology. For example, describing an accident as "a release of sarin due to an unplanned detonation of munitions in the primary combustion chamber of the dunnage furnace that subsequently caused a loss of pressure and a breach of containment" should be phrased in more understandable terms. Greater understanding would be conveyed by stating: "An exploding shell in an incinerator caused a vapor cloud of nerve agent to be released at the incineration plant."

\section{Accuracy}

Every hazard notification message should contain timely and accurate information. If the respondents in a community suspect that they are not receiving the "whole truth" about the chemical accident, people who are at risk may not believe the advice contained in the messages and refrain from taking the appropriate emergency protective actions.

\section{Frequency of Dissemination}

Frequency at which hazard notification messages are released to respondents depends on the specific conditions existing at each chemical accident. Dissemination frequency must be governed by the dynamics of the emerging hazard, severity of the risk from the hazard to population, and the amount of increasing or changing knowledge about the accident. In general, 
increased frequency of hazard notification messages informs more respondents in a shorter period of time.

Frequently repeating notification messages (e.g., "this message will be repeated over this same station every five minutes with new updates as information becomes available") focuses respondents' attention on official hazard information, reduces rumors, and helps convince the population to believe in the existence of the hazard.

\section{PREPARING MESSAGE PROTOCOLS}

Message formats will depend on the nature of the chemical threat, the specific populations at risk, the protective action strategies, local population characteristics, and the local geography and related topographic features. There is no single set of generic messages that can be routinely applied to all situations. Messages may be developed to be recorded and played when an emergency occurs. Such messages need to be tied to pre-defined emergency scenarios, such as to rapidly evolving events that require immediate response decisions and actions to maximize safety. Otherwise, generic message texts act as a template for quickly preparing a message to be broadcast. For maximum clarity, that generic text should be completed prior to an emergency.

The following messages provide some generic formats that can be adapted for use in the CSEPP. The messages will require further work to accommodate local warning and protective action strategies developed for the individual site programs. Other valuable information such as listing the page numbers for emergency instructions in telephone books may be useful. Inserts reflecting changes in conditions should also be incorporated into the warning messages. For example, when a message is broadcast a second or third time it may be appropriate to insert, "This is a repeat message" or "This is an updated message" after the phrase "This is not a test." 


\section{SAMPLE EBS MESSAGE: ALERT}

Attention, all citizens of county (or counties).

This is the Emergency Broadcast System. This is not a test.

The Emergency Broadcast System has been activated because there are conditions at the Army Depot which could develop into an emergency. At this time no releases of hazardous chemicals have occurred. The conditions that have led to this alert are described as follows:

This emergency broadcast message is not a test.

Depot and county officials, who are closely monitoring the situation, have activated the Emergency Broadcast System to alert people in the immediate response zone of a possible emergency. If you live or work in the immediate response zone, stay tuned to this station for further information.

The immediate response zone is a mile radius around the facility. It is bounded by on the west, on the north, on the east

and on the south.

At this time there is no need for people who live in the immediate response zone to take precautionary actions. If action becomes necessary, you will be informed immediately. When the Depot has the situation under control you will be also informed so you can continue with normal activities.

If you are outside the immediate response zone you do not need to take any precautionary action. If you do not know which zone you are in, or what to do in a chemical emergency, you should continue to listen to this station. 


\section{SAMPLE EBS MESSAGE: ALERT (continued)}

If you are within the immediate response zone you should read your emergency brochure or the emergency instructions in the telephone book. Further actions that may become necessary include evacuation or taking shelter in what ever structure is available with the doors and windows closed and the heating or air conditioning shut off. There are instructions in the (CSEPP or other name) brochure and the telephone book on what to do if evacuation or sheltering actions are recommended. If you are unable to locate this information, instructions on such actions will be read following this message.

Once again, the Army Depot is on alert status. No release of hazardous chemical agents have occurred. Officials are closely monitoring the situation. The Emergency Broadcast System will broadcast this message every 15 minutes over this radio station until new information becomes available. Stay tuned to this station for the latest official information.

(Read emergency instructions)

Once again, the Army Depot is now on alert status. No release of hazardous chemicals have occurred and of ficials are closely monitoring the situation.

This message will be repeated every 15 minutes over this radio station until new information becomes available. Stay tuned to this station for the latest official information. 


\section{SAMPLE EBS MESSAGE: NO ACTION IN \\ PROTECTIVE ACTION ZONE (PAZ)}

Attention, all citizens of county (counties).

This is the Emergency Broadcast System. This is not a test.

The Emergency Broadcast System has been activated because conditions at the Army Depot could develop into an emergency.

The conditions that have led to this emergency are described as follows:

This emergency broadcast message is not a test.

The situation at the Depot has led (may lead) to a release of (chemical name), which is a hazard to humans if inhaled or comes in contact with human skin.

Depot and local officials, who are closely monitoring the situation, advise that persons in the immediate response zone around the Depot should take action. These actions are:

The immediate response zone consists of a mile radius around the Army Depot, bounded by on the west, on the north, on the east, and on the south.

If you live in the protective action zone, the area just outside the immediate response zone, you should stay indoors and listen to the Emergency Broadcast Station. You are safe if you are in the protective actions zone and will not be exposed to any chemical agent. Do not attempt to evacuate.

The protective action zone is an area extending from a mile radius to a mile radius around the Army Depot. The protective action zone is bounded by on the west, on the north, on the east and on the south. 


\section{SAMPLE EBS MESSAGE: NO ACTION IN PROTECTIVE ACTION ZONE (PAZ) (continued)}

If you do not know which zone you are in or what to do in a chemical emergency you should continue to listen to this :adio station. You can also consult your telephone book for instructions (or your CSEPP brochure) on what to do in an chemical emergency.

If you are required to take further actions, officials will recommend either that you evacuate outside of the vulnerable zone or stay indoors with the doors and windows closed and the heating or air conditioning shut off. Instructions are contained in the telephone book on what to do if either of these actions are recommended. These instructions will be read at the end of this message.

This message will be repeated every 5 minutes over this radio station until new information becomes available. Please stay tuned to this station. 


\section{SAMPLE EBS MESSAGE: PRECAUTIONARY SHELTERING}

Attention, all citizens of county (counties).
This is the Emergency Broadcast System. This is not a test.

The Emergency Broadcast System has been activated due to an emergency at the Army Depot.

This emergency broadcast is not a test.

Depot officials report that there has been a minor release of the chemical agent named The conditions are described as follows:

Any downwind concentrations of the chemicals will be at levels that will not, we repeat, will not cause any harmful health effects

Depot and county officials, who are closely monitoring the situation, have activated the Emergency Broadcast System to request that people in the immediate response zone around the Depot take protective shelter. Even though outdoor concentrations will not be at levels that cause harmful effects, sheltering indoors will provide an extra margin of safety. Do not attempt to evacuate at this time because you will risk greater exposure by going outside than if you remain indoors.

The immediate response zone includes a mile radius around the Army Depot. The immediate response zone is bounded by on the west, on the north, on the east, and on the south.

If you are outside the immediate response zone, you do not need to take any precautionary actions and can safely carry on your normal activities. If you do not know which zone you are in, or what to do in a chemical emergency, you should continue to listen to this station. 


\section{SAMPLE EBS MESSAGE: PRECAUTIONARY SHELTERING (continued)}

If you live within the immediate response zone, you should read your emergency brochure or the instructions in the telephone book on how to shelter. Following this message, these instructions will be read to you. Remember you will have the greatest protection if you follow these instructions. Do not attempt to evacuate at this time because you will have a greater chance for exposure to the hazardous material. Officials will inform you if there is a need to take any further action.

Please stay tuned to this station.

(Read instructions for sheltering)

Once again, officials have recommended that people in the immediate response zone outside the Army Depot take shelter immediately.

This message will be repeated every 5 minutes over this radio station until new information becomes available. Stay tuned to this station for the latest official information. 


\section{SAMPLE EBS MESSAGE: \\ IMMEDIATE RESPONSE ZONE EVACUATION (IRZ)}

Attention, all citizens of county (counties).

This is the Emergency Broadcast System. This is not a test.

The Emergency Broadcast System has been activated due to an emergency situation at the Army Depot.

This emergency broadcast is not a test.

The situation at the Army Depot presents conditions that are hazardous to human health. The conditions for this ernergency are described as follows:

The situation has led (may lead) to a release of (chemical name) which is a hazardous to human health if inhaled or comes in contact with human skin.

Depot and county officials, who are closely monitoring the situation, have activated the Emergency Broadcast System to request people in the immediate response zone around the Army Depot to evacuate immediately. People who remain in the area may be exposed to the chemical agent and breath enough vapor to cause adverse health effects.

The immediate response zone consists of a mile radius around the facility, bounded by on the west, on the north, on the east and on the south.

If you are outside the immediate response zone you can safely carry on your normal activities. However,

IF YOU LIVE IN THE IMMEDIATE RESPONSE ZONE AROUND THE DEPOT, YOU SHOULD EVACUATE MMMEDIATELY. 


\section{SAMPLE EBS MESSAGE: IMMEDIATE RESPONSE ZONE EVACUATION (IRZ) (continued)}

If you do not know in which zone you are located, you should continue to listen to this station. If you do not know what to do in an evacuation, instructions on how to evacuate will now be read. Remember you will have the greatest protection if you follow these instructions.

(Read instructions for evacuation.)

Once again people in the immediate response zone around the Army Depot, the area that is bordered by on the west, on the north, on the east and on the south, should EVACUATE IMMEDIATELY.

This message will be repeated every 5 minutes over this radio station until new information becomes available. Stay tuned to this station for the latest official information. 


\section{SAMPLE EBS MESSAGE: ZONE EVACUATION}

Attention, all citizens of county (counties).

This is the Emergency Broadcast System. This is not a test.

The Emergency Broadcast System has been activated due to an emergency situation at the Army Depot.

This emergency broadcast message is not a test.

The Emergency Broadcast System has been activated because officials say a situation has developed at the Army Depot that presents conditions hazardous to human health. The conditions are described as follows:

The situation has led (may lead) to a release of (Chemical name), a chemical known as , that is hazardous to human health if inhaled or comes in contact with human skin.

Depot and local county officials, who are closely monitoring the situation, have activated the Emergency Broadcast System to request people in the immediate response zone around the Army Depot to evacuate immediately to a safe area. People who remain in the area may be exposed to a chemical agent plume and breath enough vapor to cause adverse health effects. If you do not know which zone you are in, or what to do in a chemical emergency, you should continue to listen to this station.

The immediate response zones to evacuate extend (direction) from the Army Depot miles. The immediate response zones that should be evacuated are bounded by on the west, on the north, on the east and on the south. 
SAMPLE EBS MESSAGE: ZONE EVACUAT'ION (continued)

If you are outside the immediate response zones, you should stay where you are and remained tuned for additional information. People outside the immediate response zones will be safe. However,

IF YOU LIVE IN ZONES OF THE IMMEDIATE RESPONSE ZONE, YOU SHOULD EVACUATE IMMEDIATELY.

Instructions on evacuating are located in your local phone book. The instructions on evacuating will now be read. Remember-you will have the greatest protection if you follow these instructions.

(Read instructions for evacuation.)

Once again, people in the immediate response zones around the Depot, the area bordered by on the west, on the north, on the east, and on the north, should evacuate immediately.

This message will be repeated every 5 minutes over this radio station until new informatius becomes available. Stay tuned to this station for the latest official information. 


\section{NON-SURETY EVENT}

A Non-Surety Event is an emergency situation on-post but does not involve a chemical agent. For example, the event could involve a fire or an explosion on-post that the public might mistake for an accident involving a chemical agent. It is important that information about the situation be provided to the public to avoid the spread of rumors and to enhance credibility that when an event occurs, the public will be informed. Whether or not such events are broadcast over the EBS is the responsibility of the local authorities, but warning messages broadcast through the EBS will reach the largest number of people in the shortest amount of time and insure that facts of the event are clearly and accurately described to the public. 


\section{SAMPLE EBS MESSAGE: NON-SURETY (or NON-CHEMICAL) EVENT}

Attention, all citizens of county (counties).

This is the Emergency Broadcast System. This is not a test. The Emergency Broadcast System has been activated due to an emergency situation at the Army Depot.

This emergency broadcast message is not a test.

The Emergency Broadcast System has been activated because there have been reports of an accident at the Army Depot. No releases of chemicals hazardous to human health have occurred nor are any releases likely to occur from the event. The conditions that have led to the situation at the Depot are described as follows:

Depot and county officials, who are closely monitoring the situation, have activated the Emergency Broadcast System to inform people that conditions on the Depot are normal. There is no need for anyone to take any actions. Please stay tuned to this station for updated information on the situation.

We repeat, the activities at the Army Depot do not involve the release of chemical agents.

If this was an emergency involving a chemical agent, officials would have advised you what actions to take. Emergency instructions for chemical accidents are in your phone book. Those persons unable to locate this information can call their local phone company for a replacement copy.

This message will be repeated every five minutes. 


\section{DRAFT EVACUATION INSTRUCTIONS}

The following instructions on evacuation have been prepared by state and local of ficials for a chemical emergency. It is extremely importanc for everyone in the affected zones to leave the area in a vehicle as quickly as possible.

If you are at home and receive a message to evacuate, assemble family members at home and the pets you wish to take. If you are not at home, do not attempt to return to your home before evacuating. Do not use the telephone as this will tie up telephone lines and delay your evacuation from the area. If some family members are not at home, do not wait for them to return to leave with you. Get family members and pets that are home into a single vehicle and depart immediately after this message ends.

Do not attempt to pick children up at schools. Children are safe in school buildings and will be well taken care of by their teachers and school authorities. You will be notified where to pick them up after the evacuation is over.

Take medication and other essential items such as hearing aids with you. Common items, such as food, toiletries, clothing, and diapers, will be provided as needed at the reception centers. Do not use time locating personal items and valuables to take with you. Officials will provide security for the evacuated areas.

If you have neighbors without vehicles, offer them a ride as space permits.

If you need a ride, call Then remain indoors with your doors and windows closed and your air-conditioning and furnace units shut down. A vehicle will pick you up as soon as possible.

Drive safely while evacuating. Other people will also be evacuating. Drive carefullyofficials estimate that it will take (an hour) for the chemical agent plume to reach your area. You will be completely safe even if you drive an average speed of 10 miles per hour. Remember to keep you car windows rolled up, vents closed, your heater or airconditioner off, and your radio tuned to this station to listen for further instructions. 


\section{DRAFT EVACUATION INSTRUCTIONS (continued)}

Drive away frum the Army Depot. Suggested evacuation routes are in your telephone book. If you do not know where to go, follow traffic on the nearest evacuation route. Obey all traffic guides and roadblocks. Evacuation routes will be specified following this message.

If you are outside the Immediate Response and Protective Action Zones, do not travel toward the evacuated areas. This will place you at greater risk and delay those people in the vulnerable zones from reaching safety.

Proceed to the nearest reception center where you will immediately be checked for chemical exposure. You will also be registered at the reception center so friends and family can contact you easily. If you have no place to stay, officials at the reception centers will provide places for you. The reception centers are located at:

Stay tuned to this radio station, station , for additional information on the emergency and updates on traffic conditions while in your vehicle.

Insert specific instructions for reverse lanes or shoulder use, such as: "The following roads have been changed to one way traffic flow out of the area:

Do not attempt to use these roads except to evacuate the area. 


\section{DRAFT SHELTERING INSTRUCTIONS}

The objective of sheltering is to prepare your dwelling to provide the maximum reduction of airflow from outside to inside.

All family members and pets should go indoors immediately; if outdoors, go into the nearest sound structure. Do not use a garage, shed, barn, or other buildings that appear to have a high degree of ventilatior or that are open to the outside. If indoors, you should remain inside and not go outdoors.

If your children are in school, do not go to the school. The children are protected in the school building. Children will be taken to a reception center as soon as it is safe to do so. You may meet them at the reception centers when authorities say it is safe to do so.

Close and lock all exterior doors and windows in your residence. Close storm windows if this can be done quickly. Close all garage doors in integral or attached garages as well as doors normally left open for ventilation. Close all interior doors. These actions reduce air circulation in the residence.

Turn off the central heat, air conditioning fans, ceiling fans, kitchen hood fans, and circulating fans. Extinguish all wood or coal fires and close fireplace dampers.

If possible, stay in an interior room with no walls connected to the outside of the structure, or a room with no windows, or the room with fewest doors and windows. Listen to your tone alert radio or the Emergency Broadcast System on your television or radio. These stations are

After you are in the room, relax as much as possible and listen to notifications of the appropriate time to exit the shelter. People should be as comfortable as possible. You should sit still and not move around. Activity increases the speed of breathing, which will lead to a greater exposure to any vapors which might seep into the room.

Turn on a television or radio so you can be notified when it is safe to exit the shelter. Wait for the official notification from authorities that it is safe for you to leave the shelter. 


\section{DRAFT SHELTERING INSTRUCTIONS (continued)}

After the plume passes, exit the structure to avoid any further exposure. If the structure is not vented, additional agent that seeped into th building could be inhaled after the plume has passed. Put on long-sleeved clothing, pants and gloves. Open all windows and doors to vent the structure.

The notification system or EBS channel will provide further instructions on what to do next. Among the possibilities are:

- Immediate evacuation to a reception center for screening and processing.

- Self/buddy decontamination.

- Waiting for emergency personnel to rescue people with special vehicles. 


\section{GLOSSARY}

accident-a deviation from normal operations or activities associated with a hazard which has the potential to result in an emergency.

chemical agent-a chemical substance intended for use in military operations to kill, seriously injure, or incapacitate a person through its physiological effects. Excluded from consideration are riot control agents, chemical herbicides, smoke, and flame.

chemical accident/incident (CAI)-chemical events involving an unintentional or uncontrolled release of a chemical agent. A chemical accident results from nondeliberate acts where safety is of primary concern; chemical incidents result from deliberate acts (terrorism or criminal), where security is of primary concern.

chemical event-a term that applies to any of the following events:

a. chemical agent leaks from munitions in the chenical agent stockpile

b. discovery of an actual or suspected chemical agent munitions or container that may require emergency transportation and/or disposal

c. any release of chemical agent to the environment outside of closed systems, facilities, or devices (e.g., lab hood, glove box, munitions, and bulk containers that were specifically designed to contain chemical agents) greater than the 8-hour time weighted average standards established by U.S. Army Surgeon General, or any release resulting in exposure of personnel exhibiting clinical signs or symptoms of chemical agent exposure

d. any exposure or release of agent that does not exceed established standards but nonetheless receives media attention

e. any deliberate release of chemical agent resulting from a terrorist or criminal act

f. loss of chemical surety material (other than from deliberate destruction by an approved, authorized laboratory and demilitarization processes, including training expenditures). 
chemical event emergency notification system-a joint system of emergency notification of chemical events for off-post response. The criteria for notification is based on predicted dosage and distances. For emergency response purposes these levels are identified as follows:

Non-surety emergency - This level will be declared when events are

likely to occur or have occurred that may be perceived as a chemical surety emergency or that may be of general.public interest but pose no chemical surety hazard. Action is notification to IRZ designated points of interest.

Limited Area Emergency - This level will be declared when the predicted chemical agent no-effects dosage does not extend beyond the chemical limited area where the event occurred. Action is notification of the IRZ, PAZ, and State- designated points of contact. IRZ emergency response officials may go to a level of increased readiness in the event of an off-post response is required.

Post Only Emergency-This level will be declared when a chemical agent no- effects dosage extends beyond the chemical limited area but does not extend beyond the installation boundaries. Action is notification of the IRZ, PAZ, and State-designated points of contact. IRZ response organizations are mobilized to be capable of immediate action. Precautionary protective actions may be initiated in potentially affected areas near installation boundary.

Community Emergency-This level is declared when the predicted chemical agent no-effects dosage extends beyond the installation boundary. Action is notification of the IRZ, PAZ, and Statedesignated points of contact. All emergency response organizations are mobilized and the IRZ and affected PAZ areas implement specified protective actions. 
chemical surety material-chemical agents and their associated weapon systems, or storage and shipping containers that have been adopted or are being considered for military use. Chemical surety materials are categorized as follows:

Category 1-Bulk nerve agent stored in 1-ton (metric) containers, isolated agent rounds (nerve and non-nerve), mines, rockets and bombs, less than items described in other categories.

Category 11 -Chemical surety material in approved demilitarization program or recovered from Army installations or from the civilian community.

Category lll-Binary munitions with both components.

Category IV-Bulk non-nerve agents stored in 1-ton containers, except those approved for demilitarization, for Research, Development, Test, and Evaluation (RDTE) projects, for surveillance, or for training.

Category V-Chemical surety material used for authorized RDTE projects, specific surveillance programs, intelligence evaluation, or scheduled training programs.

CSEPP—Chemical Stockpile Emergency Preparedness Program.

Emergency Broadcast System (EBS)-Broadcasting stations and interconnecting facilities that have been authorized by the Federal Communications Commission to operate in a controlled manner during a war, state of public peril or disaster, or other emergency as provided by the EBS plan.

Emergency Planning Zone (EPZ)-A geographic area surrounding a specific facility for which special planning and preparedness efforts are carried out to ensure the prompt and effective protective actions can be taken to reduce or minimize the impact to on-site personnel, public health and safety, and the environment in the event of an emergency; the EPZ includes both the PAZ and the IRZ. 
evacuation-a protective action which involves the orderly withdrawal of individuals from a hazardous or threatened area until such time as the area is again deemed safe for use.

immediate response zone (IRZ) - the geographic area around a hazard (disposal) site that defines the area most rapidly and severely affected by a hazard where immediate protective actions would be needed to protect the public.

message protocol-a set of conventions governing the treatment of messages notifying the public about an accident. Messages should be customized for a location and details added for the specifics of an emergency.

munitions-military armaments, weapons.

mustard gas-an irritant vesciant oily liquid used as a war gas; causes blistering of exposed tissue.

nerve agent-nerve gas; an organophosphate war gas that interferes with normal nerve transmission and induces intense bronchial spasms with resulting inhibition of respiration.

off-post-the area surrounding a military installation or facility.

off-site-the area surrounding the on-site area.

on-post-a military installation or facility.

on-site-an area around the scene of a chemical event under the operational control of the on-scene coordinator (OSC), technical escort officer, or the commander of the Initial Response Force, or the Service Response Force. On-site includes any area establishod as a National Defense Area. 
plume-airborne material spreading from a particular source; term used to denote dispersal of particles, gases, vapors, and aerosols into the atmosphere. Occasionally a plume is referred to as a cloud. A release of material into the atmosphere for short duration is also called a "puff".

Precautionary Zone (PZ)-the geographical outermost portion of the EPZ, extending from the $P A Z$ to a distance where no adverse impacts to humans would be experienced in the case of a maximum potential release under the most likely meteorological conditions.

protective action-physical measures, such as evacuation or sheltering, taken to prevent potential health hazards resulting from a release of hazardous materials to the environment from adversely affecting employees or the off-site population.

Protective action zone (PAZ)-a geographic area around a hazard site outside the IRZ in which agent exposure is unlikely but where protective actions can enhance the ability to protect the public.

release-any spilling, leaking, pumping, pouring, emitting, emptying, discharging, injecting, escaping, leaching, dumping, or disposing into the environment (including the abandonment or discharging of barrels, containers, and other closed receptacles) of any hazardous chemical, extremely hazardous substance, or other hazardous substance covered under the Comprehensive Environmental Response, Compensation, and Liability Act .

self/buddy decontamination-expedient procedures for self or for a companion that can be applied if exposure to chemical agent is suspected. These involve washing eyes and possible residue from the body and changing clothes. 
sheltering - an in-place, immediate protective action that calls for people to go indoors, close all doors and windows, turn off all sources of outside air, listen to the radio or television for emergency information, and remain indoors until official notification that it is safe to go outdoors.

source of information-source refers to an knowledgeable expert and/or official giving advice or notification in transmitted messages.

source term-The amount of material available for release. 


\section{REFERENCES}

Mileti, D. and J. Sorensen. 1990. Communication of Emergency Warnings: $A$ Social Science Perspective and State-of-the-Art Assessment, Oak Ridge National Laboratory, ORNL/TM-6609, Oak Ridge, Tenn.

TRADE. 1991. Glossary and Acronyms of Emergency Management Terms, prepared for U.S. Department of Energy, Oak Ridge Associated University, ORAU 91/K37, Oak Ridge, Tenn.

U.S. Department of the Army. 1991. Chemical Accident or Incident Response and Assistance (CAIRA) Operations, Headquarters, Department of the Army, Washington, DC. 
ORNL/TM-12163

\section{INTERNAL DISTRIBUTION}

1. M. V. Adler

2. S. A. Carnes

3. Central Research Library

4-13. C. J. Coomer

14. E. D. Copenhaver

15. Document Reference Section

16. K. S. Gant

17. M. A. Kuliasha

18. Laboratory Records

19. Laboratory Records, RC
20. D. P. Lombardi

21. ORNL Patent Office

22. R. M. Reed

23. D. E. Reichle

24. R. B. Shelton

25. B. L. Shumpert

26-50. J. H. Sorensen

51-75. B. M. Vogt

76. B. A. Walker

77. A. P. Watson

\section{EXTERNAL DISTRIBUTION}

78-87. K. Blackman, Federal Emergency Management Agency, 500 C Street, SW, Washington, DC, 20472

88. B. G. Buchanan, Computer Science Department, University of Pittsburgh, 206 Mineral Industries Building, Pittsburgh, Pennsylvania, 15260

89.-113. P. Cogan, Federal Emergency Management Agency, 500 C Street, SW, Washington, DC, 20472

114-138. D. Fisher, U.S. Department of the Army, Office of the Assistant Secretary, Installations, Logistics, and Environment, The Pentagon, Washington, DC, 20310

139. A. Hirsch, President, Dynamac Corporation, The Dynamac Building, 11140 Rockville Pike, Rockville, Maryland, 20852

140. H. M. Ingram, Director, Udall Center for Studies in Public Policy, The University of Arizona, 803/811 East First Street, Tucson, Arizona, 85719

141. C. D. MacCracken, President, Calmac Manufacturing Corporation, 101 West Sheffield Avenue, P. O. Box 710, Englewood, New Jersey, 07631

142. D. E. Morrison, 333 Oxford Road, East Lansing, Michigan, 48823

143. Office of Assistant Manager for Energy Research and Development, DOE-ORO, P. O. Box 2001, Oak Ridge, Tennessee, 37831-8600

144. OSTI, U.S. Department of Energy, P. O. Box 62, Oak Ridge, Tennessee, 37831

145. J. B. Shrago, Director, Office of Technology Transfer, 405 Kirkland Hall, Vanderbilt University, Nashville, Tennessee, 37240

146. M. Williams, Professor, Department of Economics, Northern Illinois University, DeKalb, Illinois, 60115 

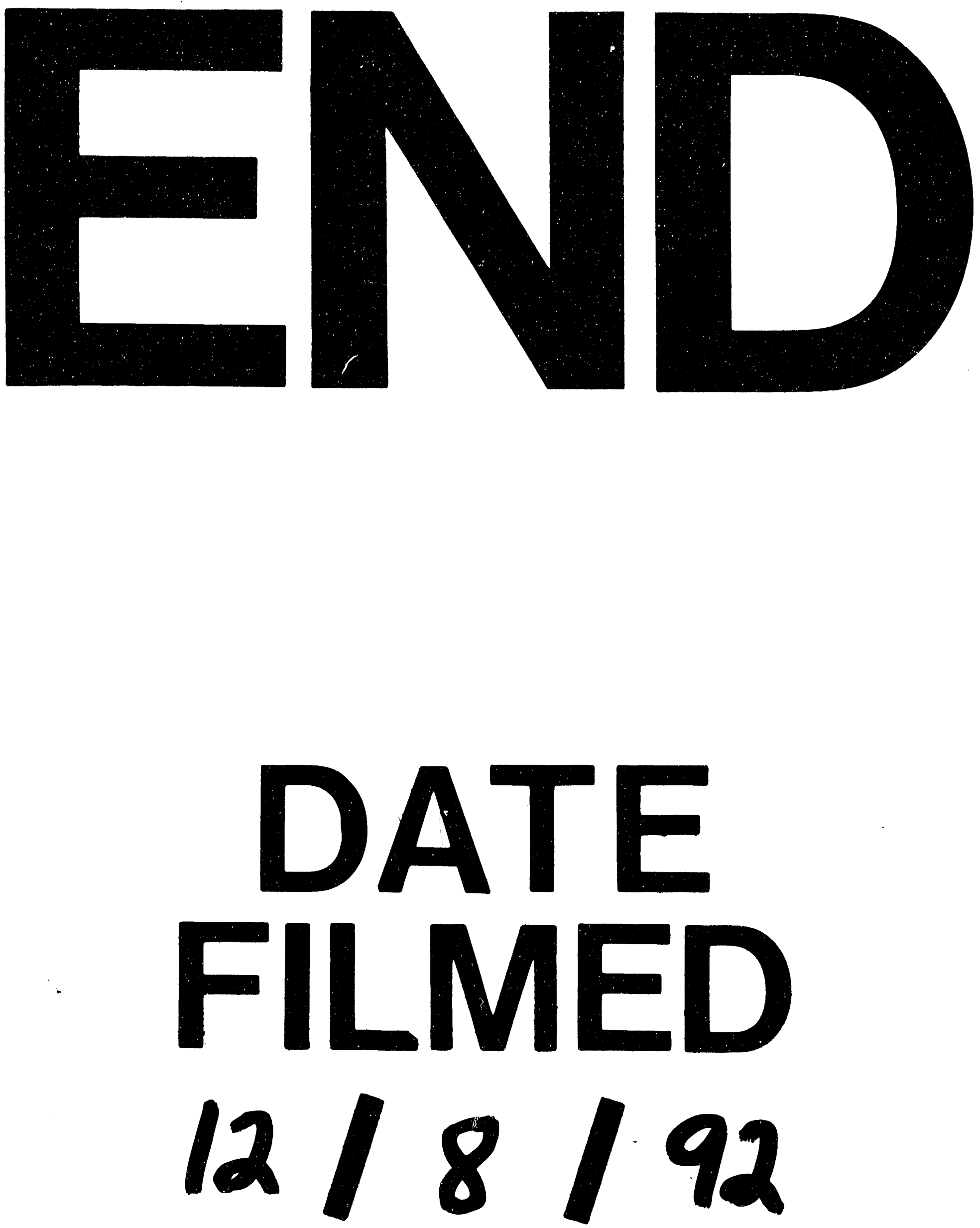
